\title{
BMJ Global Health Prioritising gender, equity, and human rights in a GRADE-based framework to inform future research on self care for sexual and reproductive health and rights
}

\author{
Nandi Siegfried (10 , ${ }^{1}$ Manjulaa Narasimhan, ${ }^{2}$ Carmen H Logie, ${ }^{3}$ Rebekah Thomas, ${ }^{4}$ \\ Laura Ferguson, ${ }^{5}$ Kevin Moody, ${ }^{6}$ Michelle Remme ${ }^{7}$
}

To cite: Siegfried N,

Narasimhan M, Logie $\mathrm{CH}$, et al. Prioritising gender, equity, and human rights in a GRADEbased framework to inform future research on self care for sexual and reproductive health and rights. BMJ Global Health 2020:5:e002128. doi:10.1136/ bmjgh-2019-002128

Handling editor Seye Abimbola

Received 30 October 2019 Revised 28 January 2020 Accepted 15 February 2020
Check for updates

(C) Author(s) (or their employer(s)) 2020. Re-use permitted under CC BY. Published by BMJ.

For numbered affiliations see end of article.

Correspondence to Dr Nandi Siegfried; nandi.siegfried@gmail.com

\section{ABSTRACT}

Introduction In January 2019, the WHO reviewed evidence to develop global recommendations on self-care interventions for sexual and reproductive health and rights (SRHR). Identification of research gaps is part of the WHO guidelines development process, but reliable methods to do so are currently lacking with gender, equity and human rights (GER) infrequently prioritised.

Methods We expanded a prior framework based on Grading of Evidence, Assessment, Development and Evaluation (GRADE) to include GER. The revised framework is applied systematically during the formulation of research questions and comprises: (1) assessment of the GRADE strength and quality rating of recommendations; (2) mandatory inclusion of research questions identified from a global stakeholder survey; and (3) selection of the GER standards and principles most relevant to the question through discussion and consensus. For each question, we articulated: (1) the most appropriate and robust study design; (2) an alternative pragmatic design if the ideal design was not feasible; and (3) the methodological challenges facing researchers through identifying potential biases.

Results We identified 39 research questions, 7 overarching research approaches and 13 discrete feasible study designs. Availability and accessibility were most frequently identified as the GER standards and principles to consider when planning studies, followed by privacy and confidentiality. Selection and detection bias were the primary methodological challenges across mixed methods, quantitative and qualitative studies. A lack of generalisability potentially limits the use of study results with non-participation in research potentially highest in more vulnerable populations.

Conclusion A framework based on GRADE that includes stakeholders' values and identification of core GER standards and principles provides a practical, systematic approach to identifying research questions from a WHO guideline. Clear guidance for future studies will contribute to an anticipated 'living guidelines' approach within WHO. Foregrounding GER as a separate component of the framework is innovative but further elaboration to operationalise appropriate indicators for SRHR self-care interventions is required.

\section{Key questions}

What is already known?

- Reliable methods to identify research gaps from WHO guidelines are lacking with gender, equity and human rights (GER) infrequently prioritised when formulating future research questions.

What are the new findings?

- A prior Grading of Evidence, Assessment, Development and Evaluation (GRADE)-based framework was revised to include mandatory stakeholder input and selection of relevant GER standards and principles and successfully applied to a WHO guideline on self-care interventions for sexual and reproductive health and rights (SRHR).

- 39 research questions, 6 research approaches and 16 discrete study designs for SRHR self-care were identified and the key methodological issues outlined.

- Availability and accessibility were the GER standards and principles most frequently identified as relevant.

What do the new findings imply?

- Application of the GRADE-informed framework to future WHO guidelines development processes has potential to harmonise research question formulation and to ensure more consistent consideration of GER across the organisation.

- The dashboard outlining future SRHR studies is expected to prove useful to researchers.

\section{INTRODUCTION}

The mandate of the WHO is to develop global clinical and public health guidance that informs country-level healthcare policies, guidelines, programmes and services. The systematic process of WHO guideline development includes the identification and documentation of research gaps. ${ }^{1}$ This is intended to focus research to inform and strengthen 
new and existing WHO recommendations. However, wide variation in the quality, robustness, presentation and dissemination of research priorities across sets of WHO guidelines has been noted. ${ }^{2}$ Currently within the WHO transformation process, systematic approaches to coherent research agenda formulation are being explored.

In 2018, the WHO Department of Reproductive Health and Research embarked on a process to: (1) develop evidence-based recommendations on self-care interventions for sexual and reproductive health and rights (SRHR) and (2) delineate research gaps in the field. A Guidelines Development Group (GDG) was established comprising experts and stakeholders active in SRHR and/ or self-care interventions. The GDG was regionally and gender representative and included representation from youth, vulnerable populations, healthcare providers, policymakers, programme managers, researchers and civil society, as well as experts in human rights, gender equality and health economics. ${ }^{3}$

The following definition of self-care was adopted for the guidelines: self-care is the ability of individuals, families and communities to promote health, prevent disease, maintain health and to cope with illness and disability with or without the support of a healthcare provider. ${ }^{4}$ The scope of self-care as described in this definition includes health promotion, disease prevention and control, self-medication, providing care to dependent persons, seeking hospital/ specialist care if necessary and rehabilitation including palliative care.

Members of the GDG attended a scoping meeting in March 2018 to prioritise and refine the self-care interventions to be evaluated in the guideline and to reflect on discussions arising from a prior WHO-led meeting on the ethical, legal, social accountability and human rights implications of self-care interventions. ${ }^{5}$ The GDG agreed that the systematic consideration of gender, equity and human rights (GER) in the provision of selfcare interventions is key to ensuring better health for all. As defined by WHO, human rights-based approaches to health consider and address inequalities, power imbalances and discrimination, including those related to gender. ${ }^{6}$ Such approaches also aim to support better and more sustainable health and development outcomes and focus on capacity development, both of duty bearers to meet their obligations and of individuals to claim their rights. ${ }^{7}$ Attention to ways of empowering individuals and communities, particularly vulnerable populations, to understand and claim their rights requires special attention in many domains, including in research. Sridharan and colleagues $^{8}$ argue that WHO needs to develop concrete actions towards mainstreaming GER. The GDG selected the fulfilment of the following GER standards and principles as key to measuring the impact of self-care interventions in future research studies: (1) the right to highest attainable standard of health (including availability, accessibility, acceptability and quality); (2) active and fully informed participation; (3) non-discrimination;
(4) the right to seek, receive and impart information; (5) informed decision-making; (6) privacy and confidentiality; and (7) accountability. ${ }^{9}$

At a final GDG meeting in January 2019, the GDG reviewed evidence from five systematic reviews on self-care interventions in order to formulate new consensus-based self-care recommendations. ${ }^{3}$ The new recommendations covered the following topics: (1) self-injectable hormonal contraception, (2) over-thecounter oral contraception, (3) home-based ovulation predictor kits (OPKs), (4) self-sampling for human papilloma virus (HPV) and (5) self-collection of samples for sexually transmitted infections (STIs). Each recommendation was formulated in response to an a priori clinical or public health question regarding the effectiveness of the intervention when offered as an additional approach to current practice within the formal health sector. The questions were formulated using the Population, Interventions, Comparison and Outcomes (PICO) structure. ${ }^{1}$

To further inform the guidelines, the GDG also reviewed evidence from a global online survey of healthcare providers and users of healthcare services, which was hosted on the WHO website and shared via several listservs between July and October $2018 .^{10}$ The survey included a range of questions regarding respondents' values and preferences for self-care interventions for sexual and reproductive health. Three of these were interventions evaluated in the systematic reviews: (1) selfinjectable hormonal contraception, (2) oral contraception (including over the counter), and (3) self-collection of samples for STIs (including HPV). The survey reached $294(35.6 \%)$ healthcare providers and $531(64.4 \%)$ users of healthcare services from 113 countries. There was diversity in $\mathrm{WHO}$ regional representation in responses from healthcare providers (Africa 30.0\%, Europe 20.8\%, Latin America and the Caribbean 20.8\%, Asia $14.2 \%$, Northern America $13.9 \%$ and Oceania $0.3 \%$ ) and lay respondents (Europe $32.0 \%$, Africa $23.0 \%$, Asia 20.2\%, Northern America 12.9\%, Latin America and the Caribbean $10.5 \%$ and Oceania $1.3 \%) .{ }^{10}$

In this article, we present a systematic approach to the formulation of research questions to guide future studies related to the five topics of the new WHO recommendations on self-care interventions. We demonstrate how evidence from systematic reviews, results from a global survey and consideration of GER, together informed question formulation. Our primary aim is to demonstrate both the feasibility and utility of using a structured process combined with a GER lens to identify research gaps within the context of developing a WHO guideline. A secondary aim is to provide researchers with a dashboard of potential evidence-informed research questions and related feasible study designs-and associated methodological challenges and GER considerations-to ensure responsive future research in the rapidly evolving field of SRHR self-care. 
Table 1 Key domains that require consideration when formulating WHO recommendations

\begin{tabular}{ll}
\hline Factor & How the factor influences the direction and strength of a recommendation \\
\hline Quality of the evidence & $\begin{array}{l}\text { The quality of the evidence across outcomes critical to decision making will inform the strength of } \\
\text { the recommendation. The higher the quality of the evidence, the greater the likelihood of a strong } \\
\text { recommendation. }\end{array}$ \\
Values and preferences & $\begin{array}{l}\text { This describes the relative importance assigned to health outcomes by those affected by them; how } \\
\text { such importance varies within and across populations; and whether this importance or variability } \\
\text { is surrounded by uncertainty. The less uncertainty or variability there is about the values and } \\
\text { preferences of people experiencing the critical or important outcomes, the greater the likelihood of } \\
\text { a strong recommendation. }\end{array}$
\end{tabular}

$\begin{array}{ll}\begin{array}{l}\text { Balance of benefits } \\ \text { versus harms }\end{array} & \begin{array}{l}\text { This requires an evaluation of the absolute effects of both benefits and harms (or downsides) of } \\ \text { the intervention and their importance. The greater the net benefit or net harm associated with an } \\ \text { intervention or exposure, the greater the likelihood of a strong recommendation in favour or against } \\ \text { the intervention. }\end{array} \\ \begin{array}{l}\text { Resource implications } \\ \text { This pertains to how resource intense an intervention is, whether it is cost-effective and whether } \\ \text { it offers any incremental benefit. The more advantageous or clearly disadvantageous the resource } \\ \text { implications are, the greater the likelihood of a strong recommendation either for or against the } \\ \text { intervention. }\end{array} \\ \begin{array}{l}\text { The problem's priority is determined by its importance and frequency (ie, burden of disease, disease } \\ \text { prevalence or baseline risk). The greater the importance of the problem, the greater the likelihood of } \\ \text { a strong recommendation. }\end{array} \\ \begin{array}{l}\text { Equity and human rights } \\ \text { The greater the likelihood that the intervention will reduce inequities, improve equity or contribute to } \\ \text { the realisation of one or several human rights as defined under the international legal framework, the } \\ \text { greater the likelihood of a strong recommendation. }\end{array} \\ \begin{array}{l}\text { The greater the acceptability of an option to all or most stakeholders, the greater the likelihood of a } \\ \text { strong recommendation. }\end{array} \\ \begin{array}{l}\text { The greater the feasibility of an option from the standpoint of all or most stakeholders, the greater } \\ \text { the likelihood of a strong recommendation. Feasibility overlaps with values and preferences, } \\ \text { resource considerations, existing infrastructures, equity, cultural norms, legal frameworks and many } \\ \text { other considerations. }\end{array}\end{array}$

Reproduced from the WHO $2014 .^{1}$

\section{METHODS}

We adopted a similar methodological approach to research formulation used in two previously published WHO guidelines. ${ }^{112}$ Prior to the GDG meeting, a systematic review, including meta-analysis where appropriate, was conducted for each of the five selected PICO questions. ${ }^{13-17}$ The overall certainty of evidence was rated as high, moderate, low or very low according to the Grading of Evidence, Assessment, Development and Evaluation (GRADE) approach. ${ }^{18}$ The certainty of evidence is dependent on the risk of bias, precision, consistency, directness of the results and other considerations such as publication bias. During the meeting, the GDG formulated a recommendation in response to the following GRADE domains: certainty of the evidence, balance of benefits and harms, resource use implications, user values and preferences, acceptability among healthcare providers and key stakeholders, feasibility, equity and human rights (See table 1). Recommendations were then further categorised by the GDG as strong or conditional. In general, strong recommendations are made when the quality of evidence is high and the benefits of an intervention clearly outweigh the harms, whereas conditional recommendations recognise that the quality of the evidence is low or that specific country contextual factors may determine the uptake of a recommendation. ${ }^{19}$

We used the GRADE framework as a starting point as it allows determination of research gaps based on the strength of the recommendation and the certainty of the evidence. For example, identification of a conditional recommendation, or low or very low certainty evidence, regardless of the strength of the recommendation, is indicative of where further research is required (see figure 1).

Previously, we had expanded the GRADE framework and included an additional component specific to the values and preferences of the community of users and potential users the recommendations intend to serve. ${ }^{12}$ We applied this step to the current guidelines on selfcare interventions and reviewed results from the WHOcommissioned global online survey of users of sexual and reproductive self-care interventions. ${ }^{3}$ In addition, we captured specific research gaps identified by GDG participants during dedicated sessions at both the scoping and guidelines development meetings. We then viewed each research question through a GER lens and through discussion and consensus between authors of this paper identified the GER standards and principles 


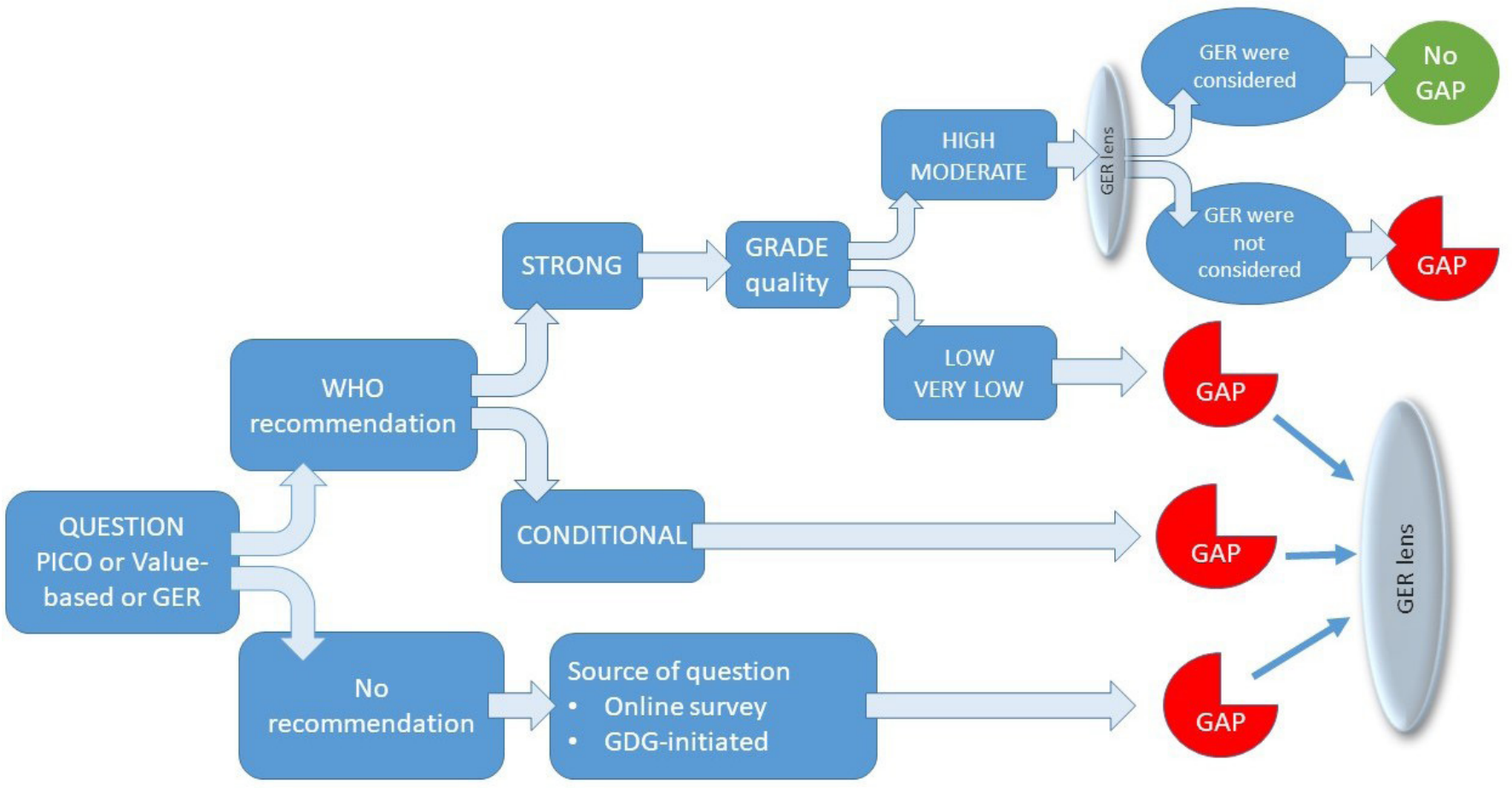

Figure 1 Hierarchical decision making algorithm to formulate research questions based on the presence and strength of a WHO recommendation, combined with the source of the question. GDG, Guidelines Development Group; GER, gender, equity and human rights; PICO, Population, Interventions, Comparison and Outcomes.

essential to consider and measure when planning future research.

Following the GDG meeting, for each a priori PICO question, and for additional research questions identified from the global survey and during the meeting, we tabulated the following:

1. The clinical, programmatic, values-based or GER research question.

2. The related recommendation formulated by the GDG (or a record that no recommendation was made) where applicable.

3 . The strength of each recommendation where applicable.

4. The certainty of the evidence underpinning the recommendation where applicable.

5. The GER standards and principles most relevant to the question as discussed during the scoping and guideline development meetings and agreed on by authors of this paper.

From the above, a research gap was identified when one or more of the following conditions was met: (1) the recommendation was conditional; or (2) the certainty of evidence was low or very low (even in the presence of a strong recommendation); or (3) key GER principles were not considered or absent (even if the certainty of evidence was moderate or high for clinical or public health effectiveness outcomes); or (4) no recommendation was made and the GDG or survey had articulated a research gap during their deliberations. We also identified a gap for strong recommendations if the evidence only arose from well-resourced settings. For each identified research gap, the authors then tabulated the following:

6 . The most robust study design to answer the research question(s), including identification of GER principles to consider.

7. Conceptualisation of a pragmatic alternative study design if the ideal design was not feasible.

8. Consideration of the methodological challenges of the alternative study design with the potential bias(es) identified.

Following tabulation, we categorised the primary focus of each research question according to the relevant GRADE domain as outlined in table 1 .

\section{Patient and public involvement}

Participation of the public in developing research gaps was achieved in several ways: (1) through completion of the global survey, (2) members of several civil society associations contributed to the GDG meeting as participants on the GDG, (3) one of the authors is a patient representative and (4) all authors identify as individuals who engage or may engage with SRHR self-care interventions.

\section{RESULTS}

Tables 2-6 provide an overview of research gaps in SRHR self-care, the most relevant GER for each question and the study design(s) considered most feasible and appropriate to answer each question. Thirty-nine research questions were formulated with seven overarching research 


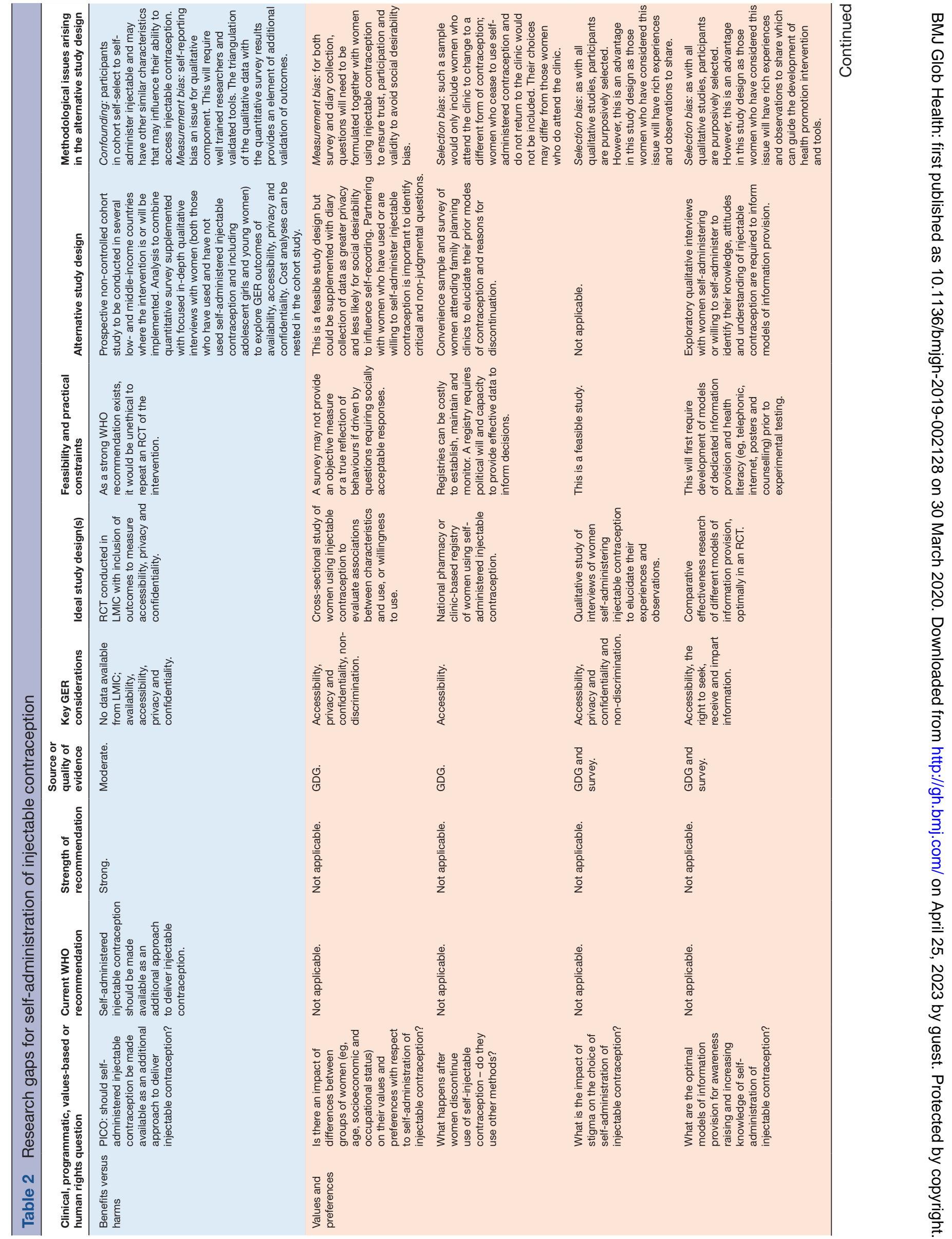




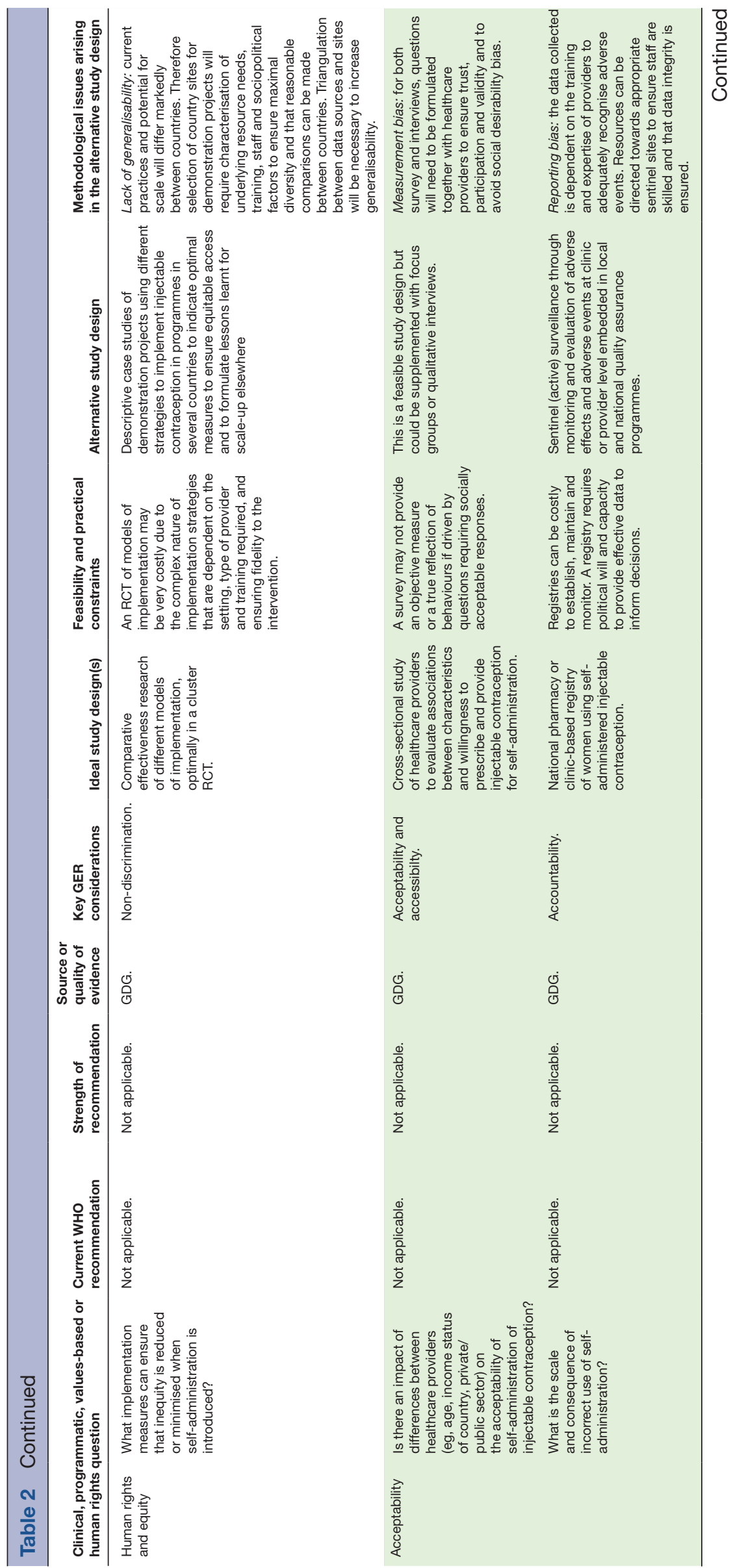

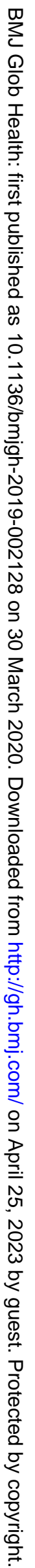




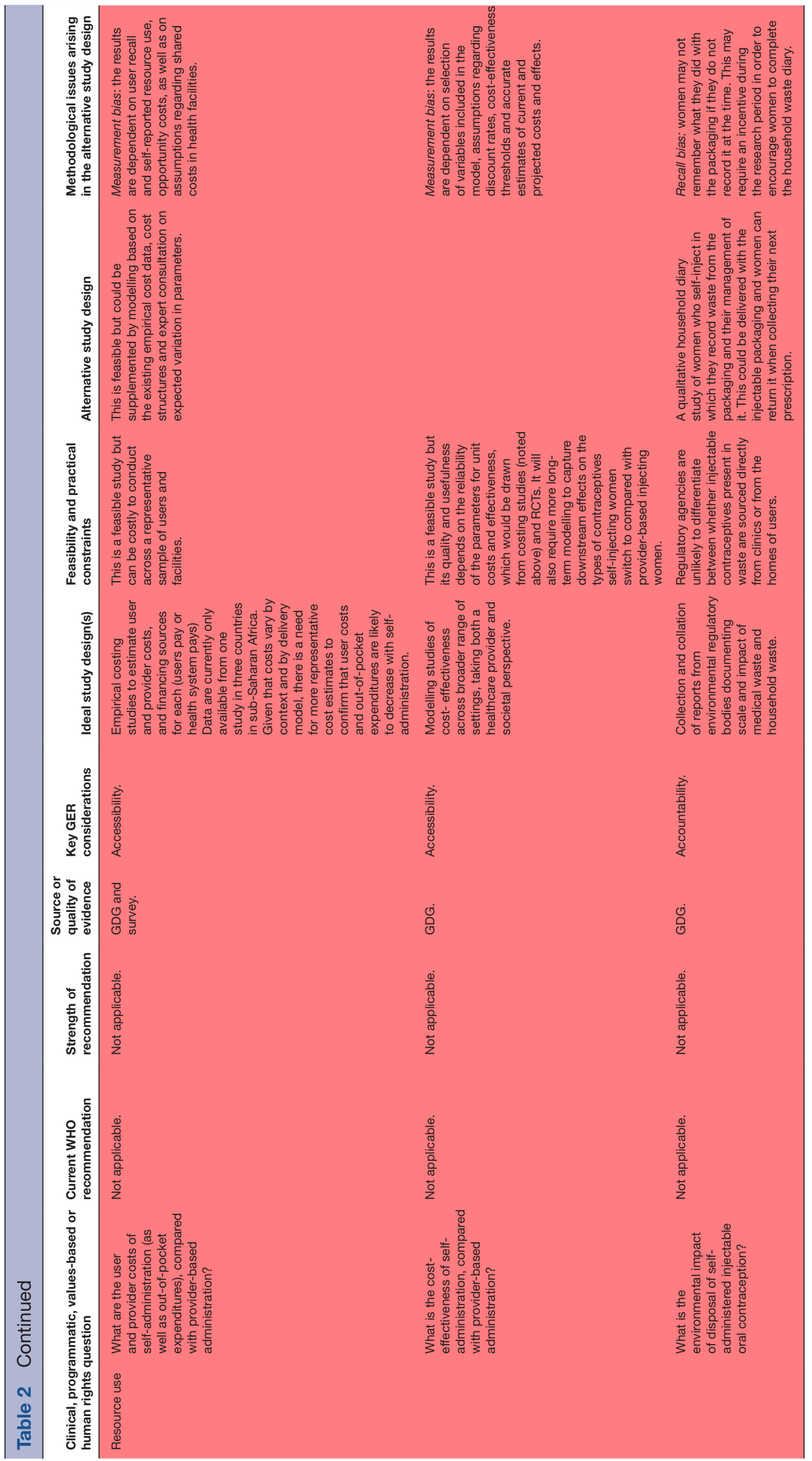

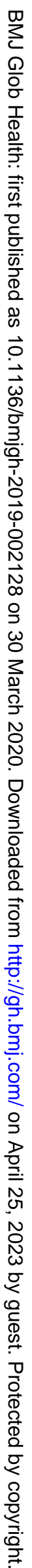




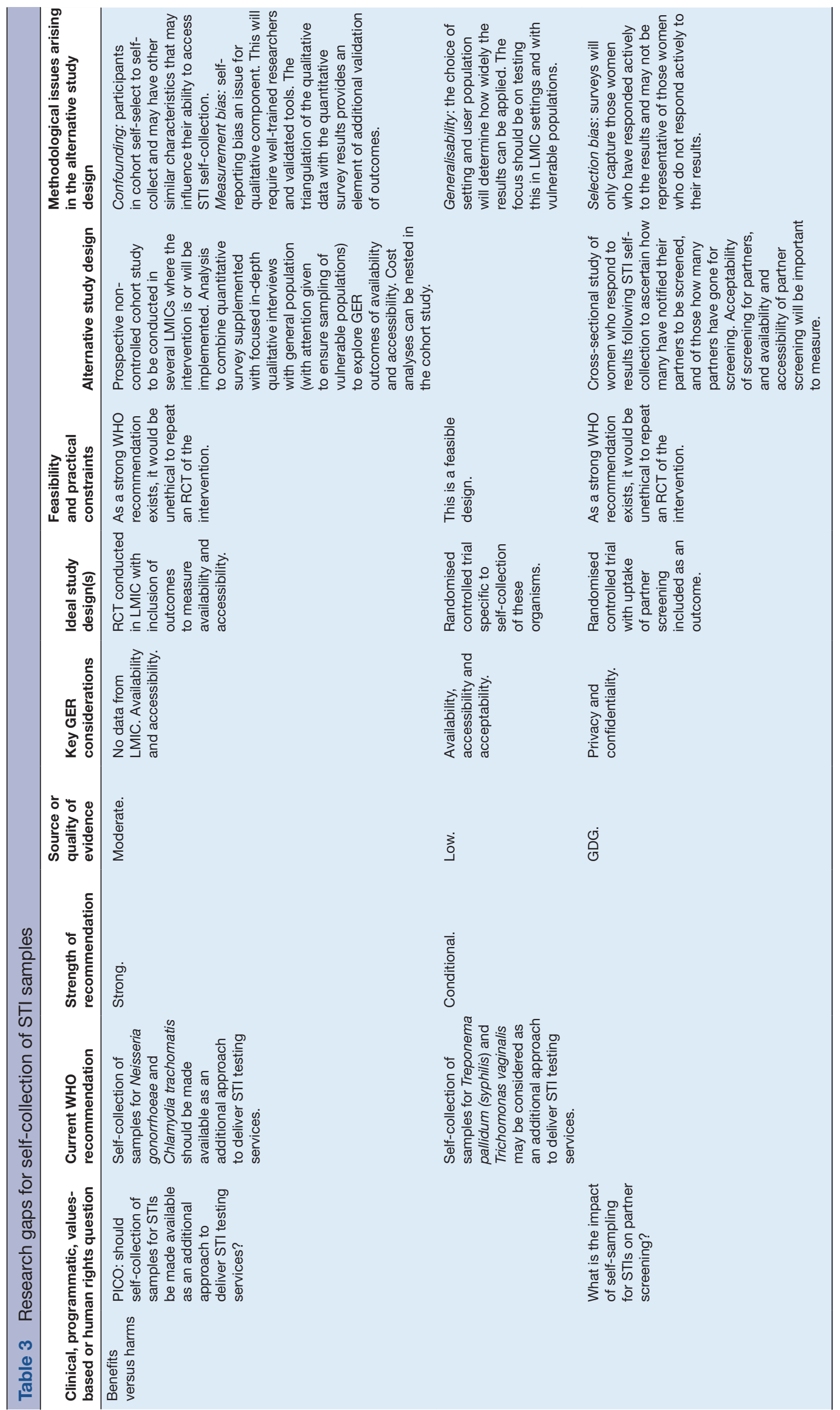




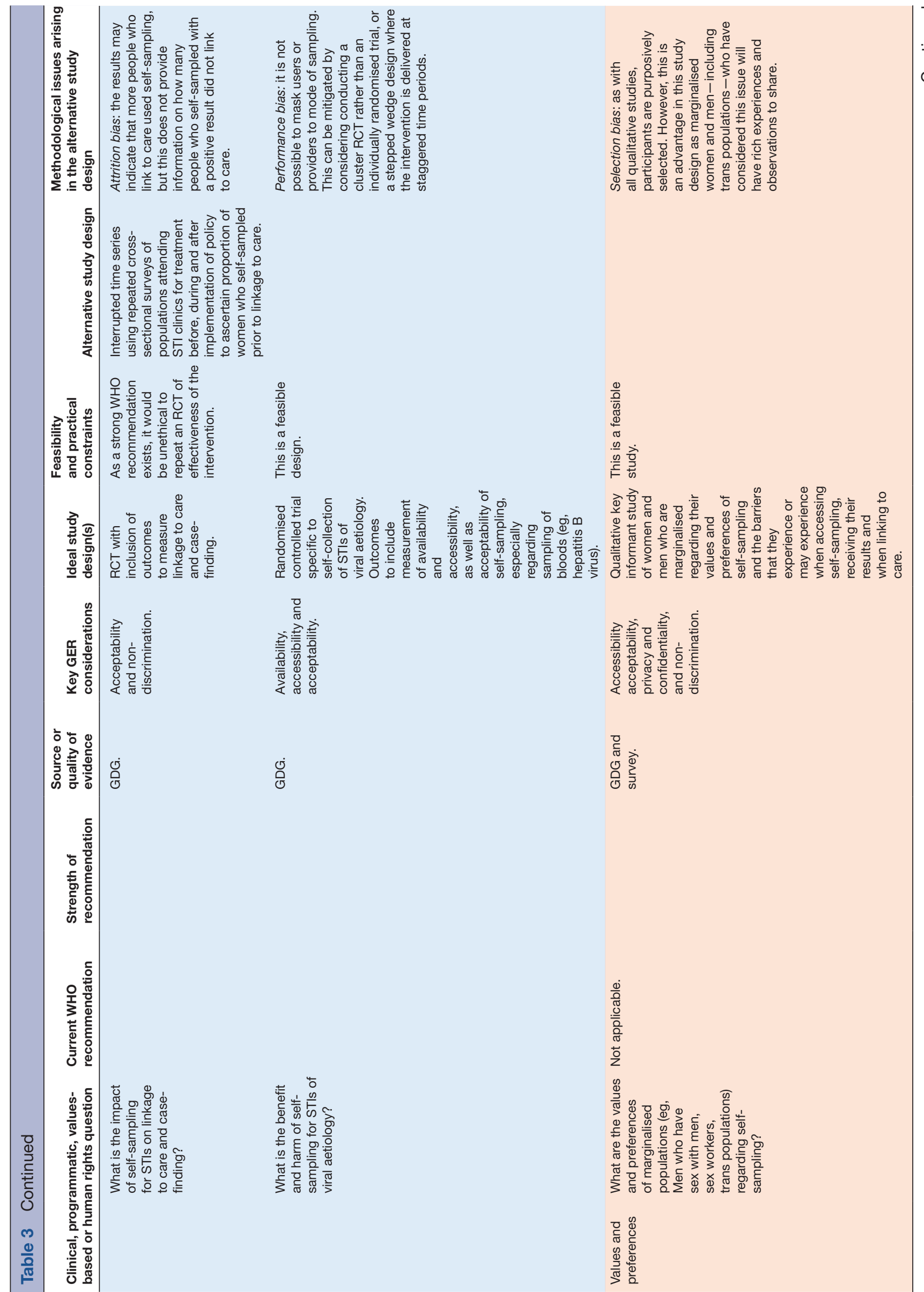




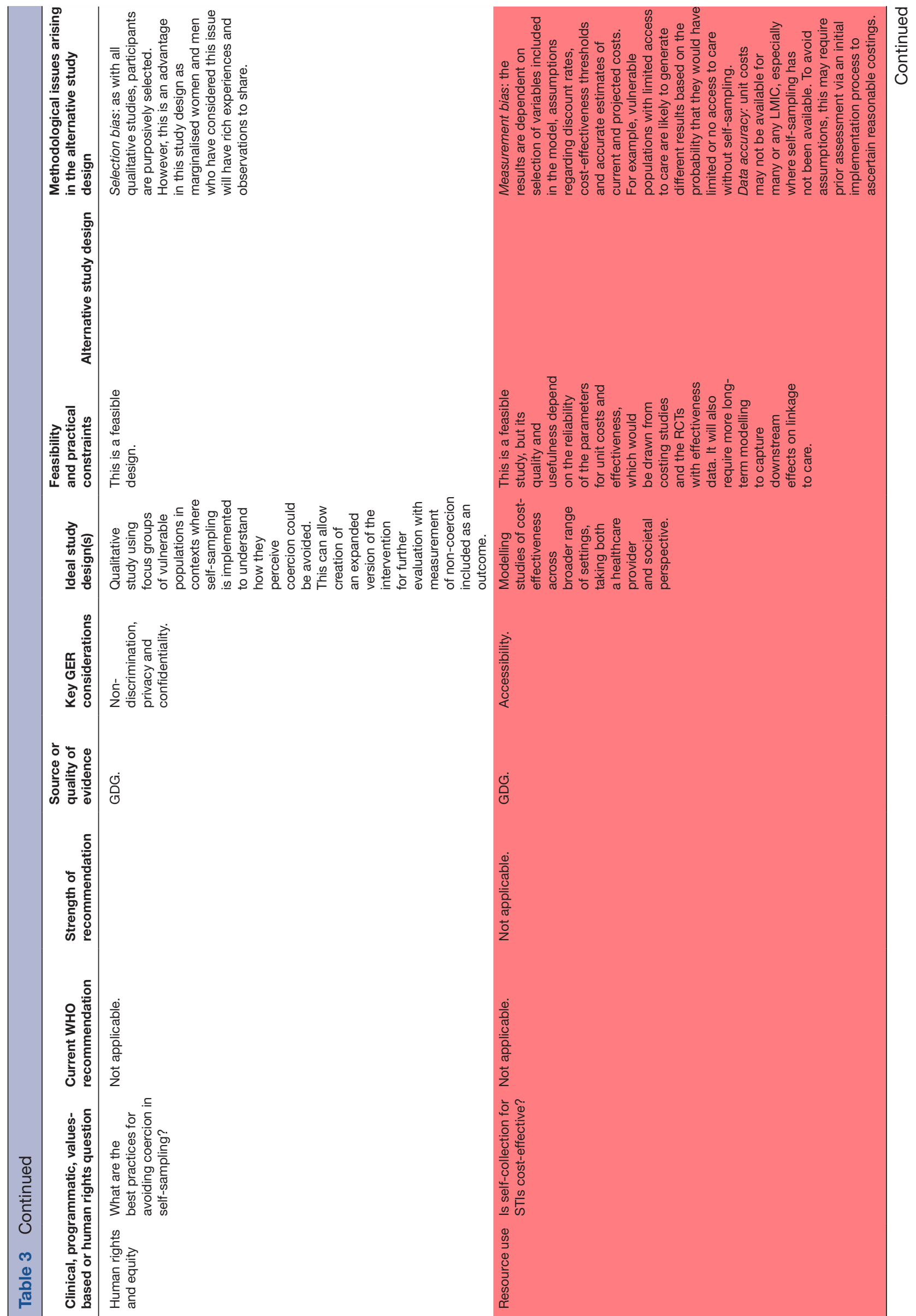




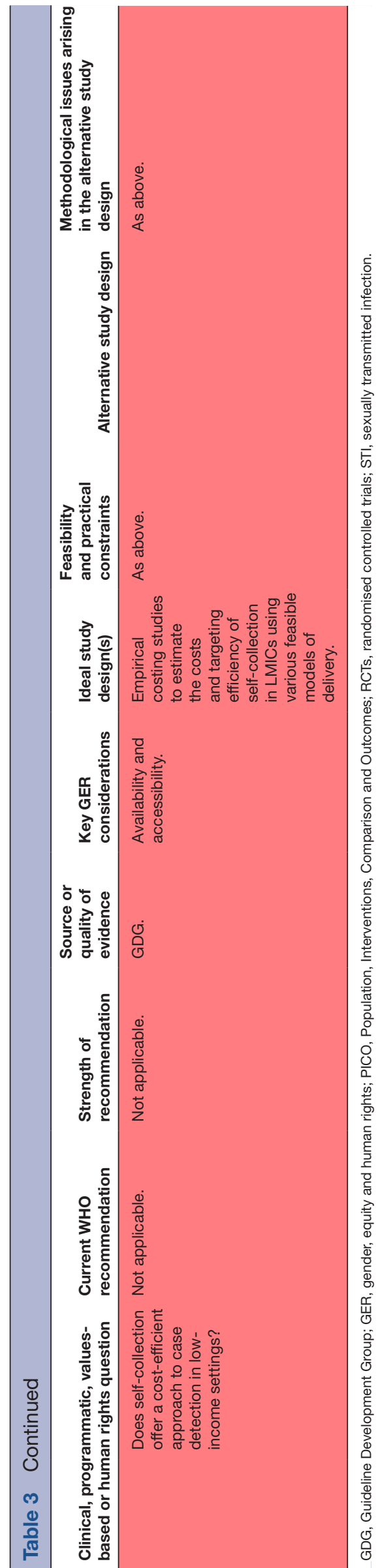

approaches and 13 discrete feasible study designs developed:

1. Survey approach (one prevalence survey; two interrupted time series; five cross-sectional studies; one household diary study).

2. Qualitative approach (seven key informant interviews; three focus groups).

3. Implementation research approach (four prospective mixed methods cohort studies; one demonstration project).

4. Comparative effectiveness research (three nonrandomised controlled trials (non-RCTs); two RCTs).

5. Economic approach (four cost-effectiveness studies; four costing studies).

6. Surveillance (one sentinel surveillance study).

7. Standard patient study (1).

We identified selection bias and detection bias as the primary methodological challenges across mixed methods, quantitative and qualitative studies. Detection bias was driven by concerns around self-reported data that may be prone to social desirability bias when participants provide answers they consider the assessors expect to hear. Selection bias in non-randomised studies limits generalisability and occurs when research participants who agree to participate differ qualitatively from those who do not agree to participate. Non-participation may be highest in those vulnerable populations who fear discrimination or have privacy and confidentiality concerns. This would then limit the utility of the results obtained from those who do participate, including in relation to GER.

The most frequent GER standards and principles considered relevant were availability and accessibility, followed by privacy and confidentiality.

\section{DISCUSSION}

We developed a structured approach to identification of research gaps and formulation of research questions and study designs during a WHO guidelines development process. Our approach builds on our previous work in this area and is rooted in the current GRADE framework used by WHO, further extending it to incorporate the user perspective and foregrounding GER throughout the process.

To the best of our knowledge, our approach is unique in providing practical systematised steps to research question formulation during WHO guideline development and elaboration of the design of future studies. Prior work in this area has been sparse and focused on identification and characterisation of research gaps arising from systematic reviews (not guidelines) and has not described the type of research that is required. ${ }^{20}$ Given that the aim of identification of research gaps is to reduce waste and increase research value,$^{21}$ collation and possible registration of research gaps on a publicly accessible platform should be encouraged to realign future studies with the existing body of evidence. This would increase access to suggested methodologies and processes to advance 


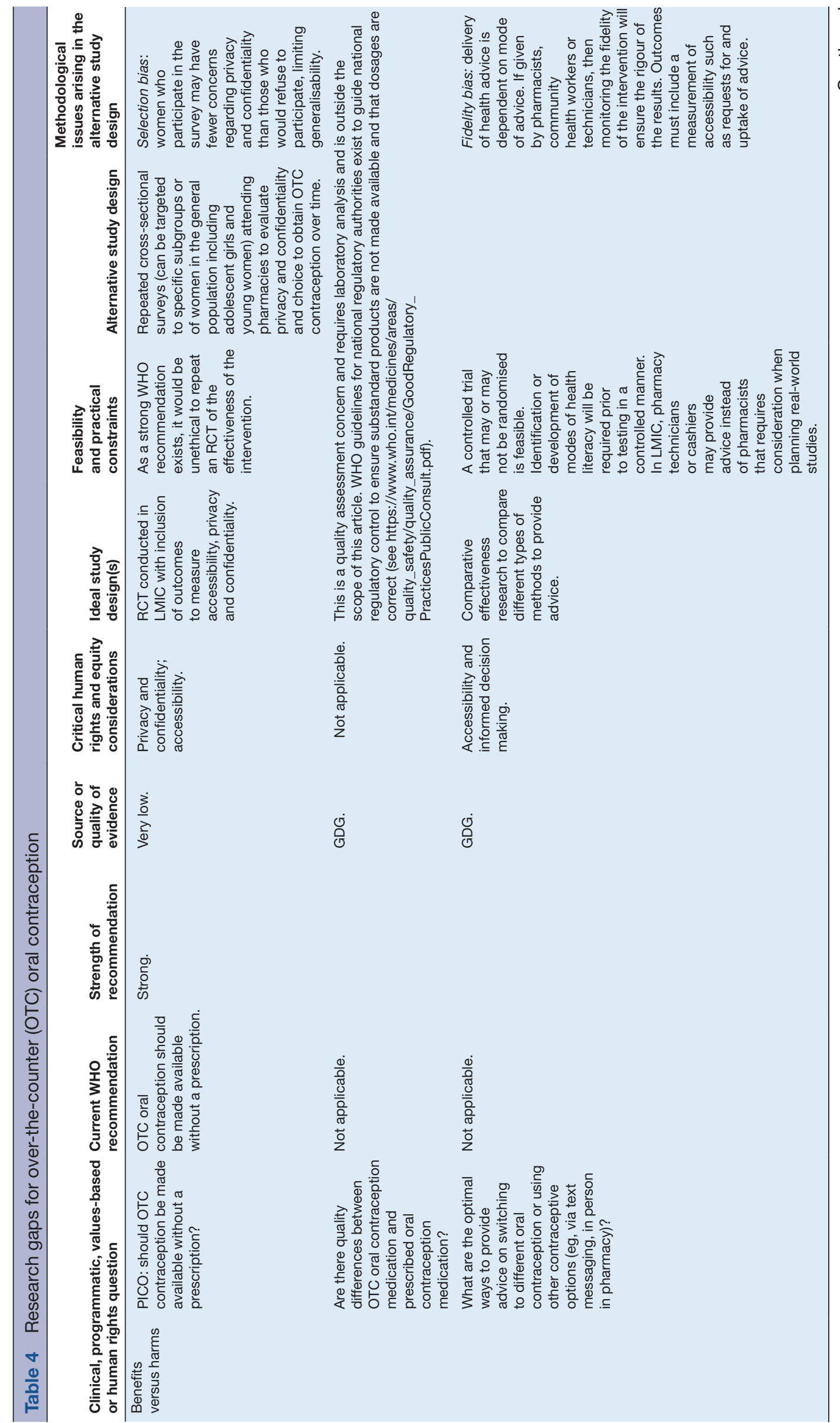

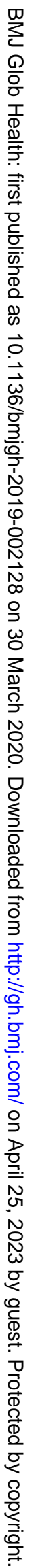




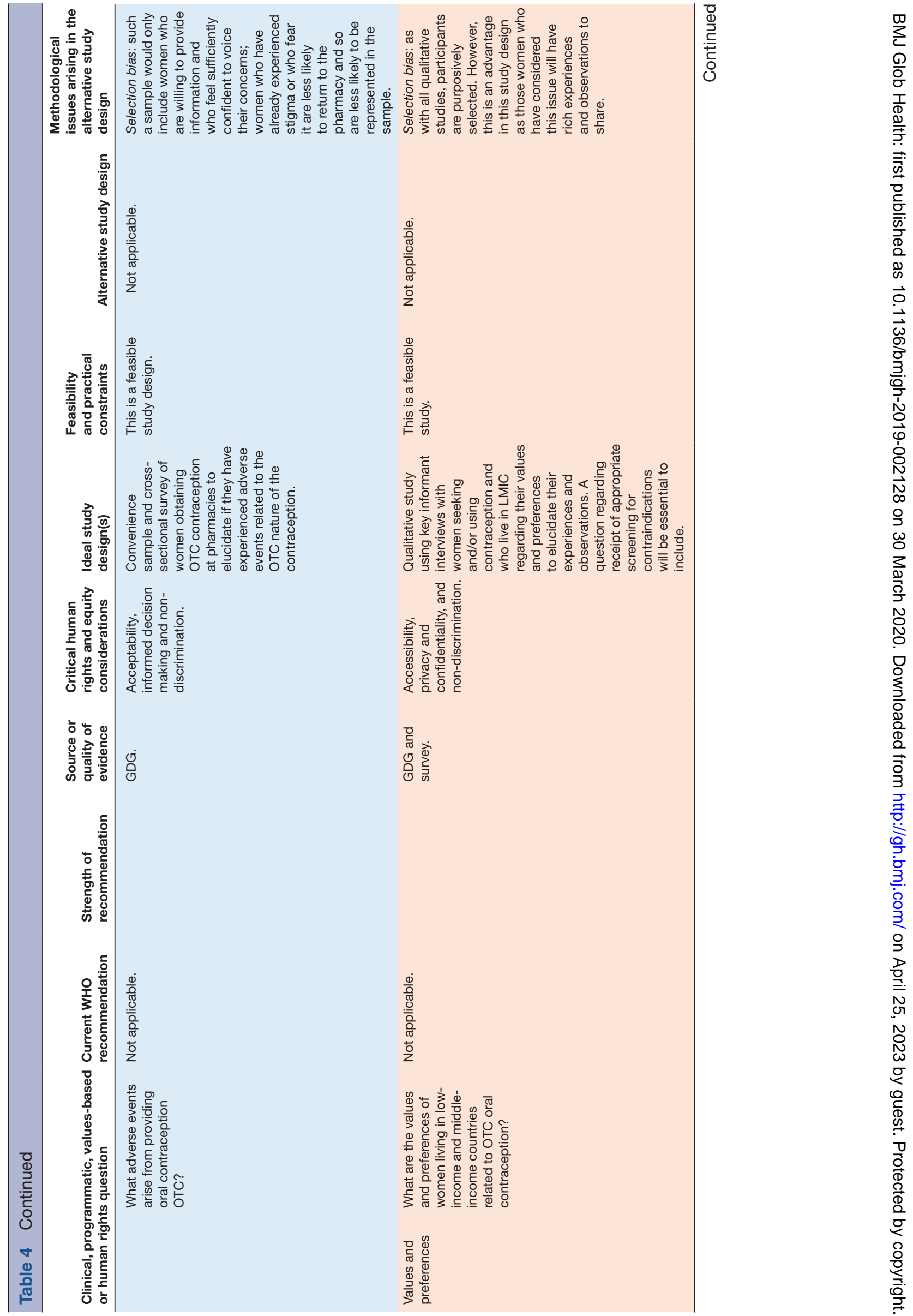




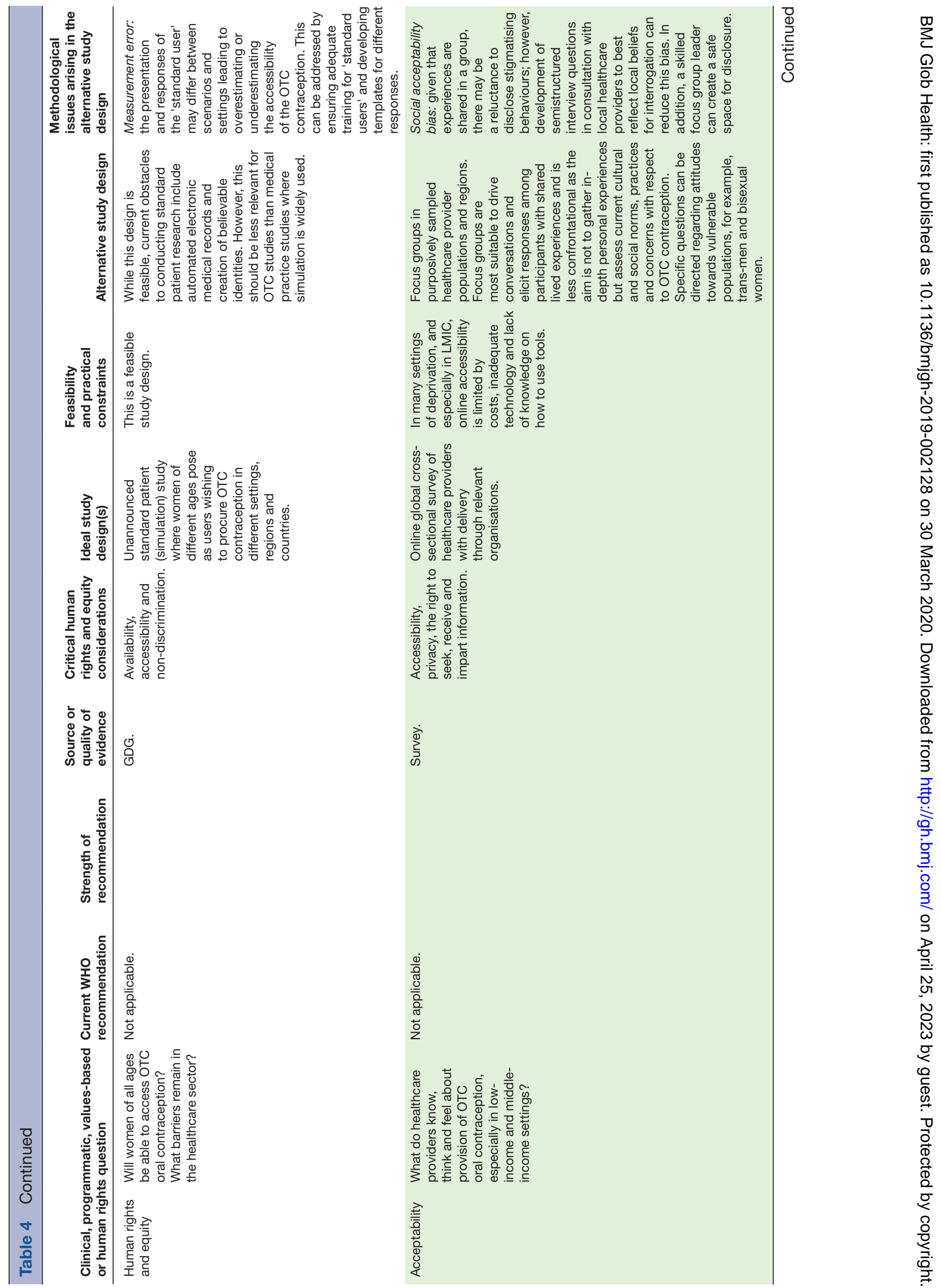




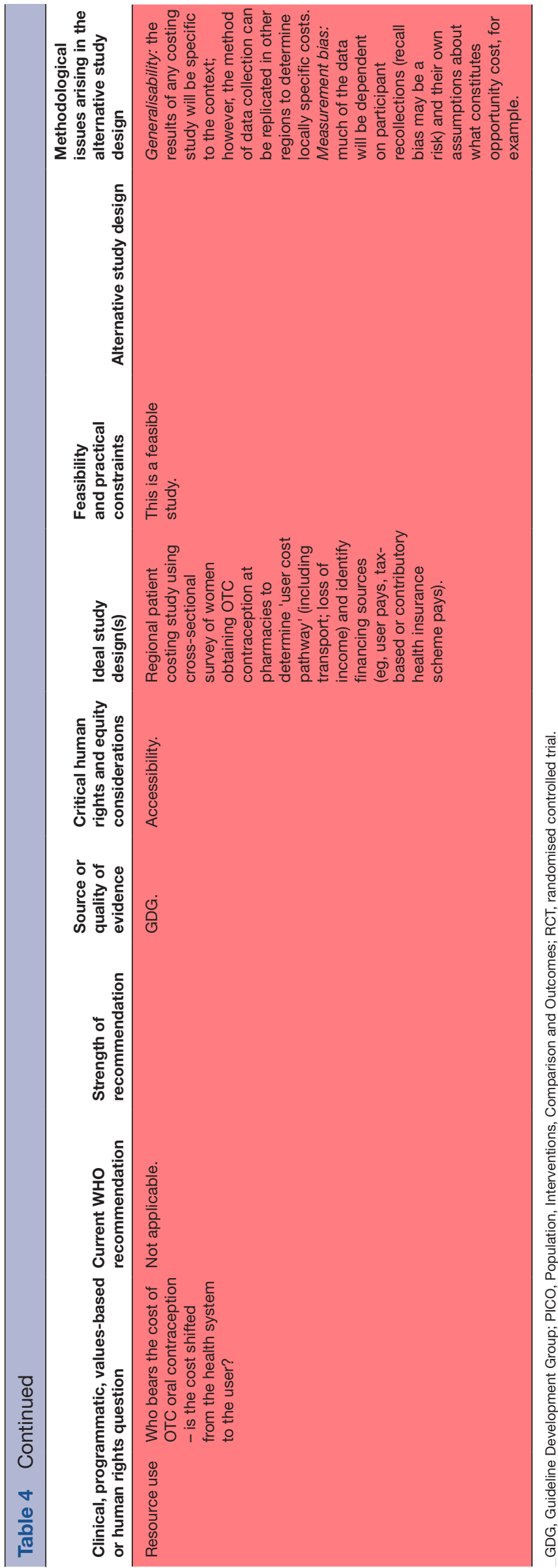

research from resource-constrained settings where we found gaps in existing evidence around self-care interventions. Given that much of the evidence reviewed came from high-income countries, it will also be important for future research in these fields to develop capacity where needed and promote research appropriate to the local contexts in low-income and middle-income countries.

The application of a 'living guidelines' approach to WHO guideline development process will ensure greater responsiveness to new research findings. ${ }^{22}$ Current guidance for formulating and prioritising research gaps during WHO guideline development processes requires strengthening in the WHO Handbook of Guideline Development. ${ }^{1}$ Research gap identification is rarely prioritised during guideline development processes and the opportunity to shape the future research agenda is missed. ${ }^{2}$ Our practical approach presents an opportunity to WHO (and other guidelines developers) to better integrate research identification and elaboration into the guidelines decision-making space, in particular research that is reflective of need and priorities. Time and cost constraints may preclude extensive discussion of research gaps during a guidelines meeting, but at a minimum a dedicated agenda item and a working group tasked to develop the research gaps further following the meeting should be considered. We can envision automation of the decision-making steps in our approach using the hierarchical model outlined in figure 1. However, we would caution that such a process be viewed as a starting point to facilitate more in-depth discussions rather than a rigid template.

GER are recognised as key considerations in the SRHR field. ${ }^{23}$ SRHR self-care interventions present many opportunities to address common obstacles to delivering equitable, gender-responsive and rights-based healthcare. Provided users are fully informed, able to make autonomous choices and are able to link to a health system when required, high-quality self-care interventions can offer available, accessible and acceptable healthcare to those individuals and groups who may be less likely to access formal healthcare due to fear of discrimination or privacy and confidentiality concerns. Benefits may flow to healthcare providers too as users become more engaged in their healthcare, with task-shifting reducing heavy workloads and consumer self-sampling potentially reducing the risk of personal injury to providers when obtaining samples (eg, via venepuncture).

We consistently identified accessibility as an important GER principle to measure across questions for all five interventions. From a human rights perspective, accessibility encompasses physical accessibility, economic accessibility (affordability), non-discrimination in access and information accessibility. ${ }^{25}$ This illustrates that multiple indicators are often required to measure a single outcome domain. Within a rights-based approach to measuring health, health indicators can be used to measure different standards and principles relating to GER. ${ }^{26}$ For example, some health surveys collect data on informed choice in 


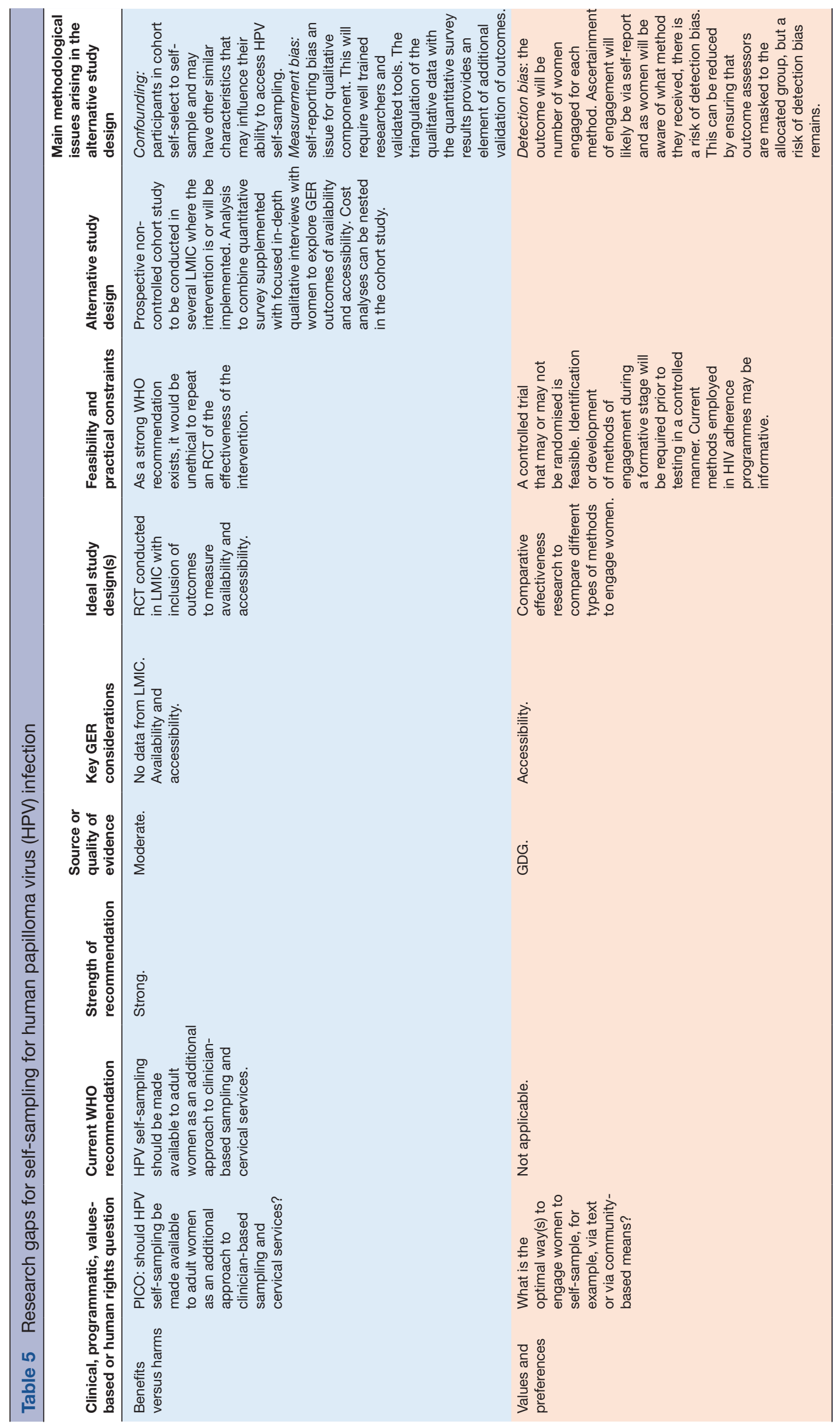




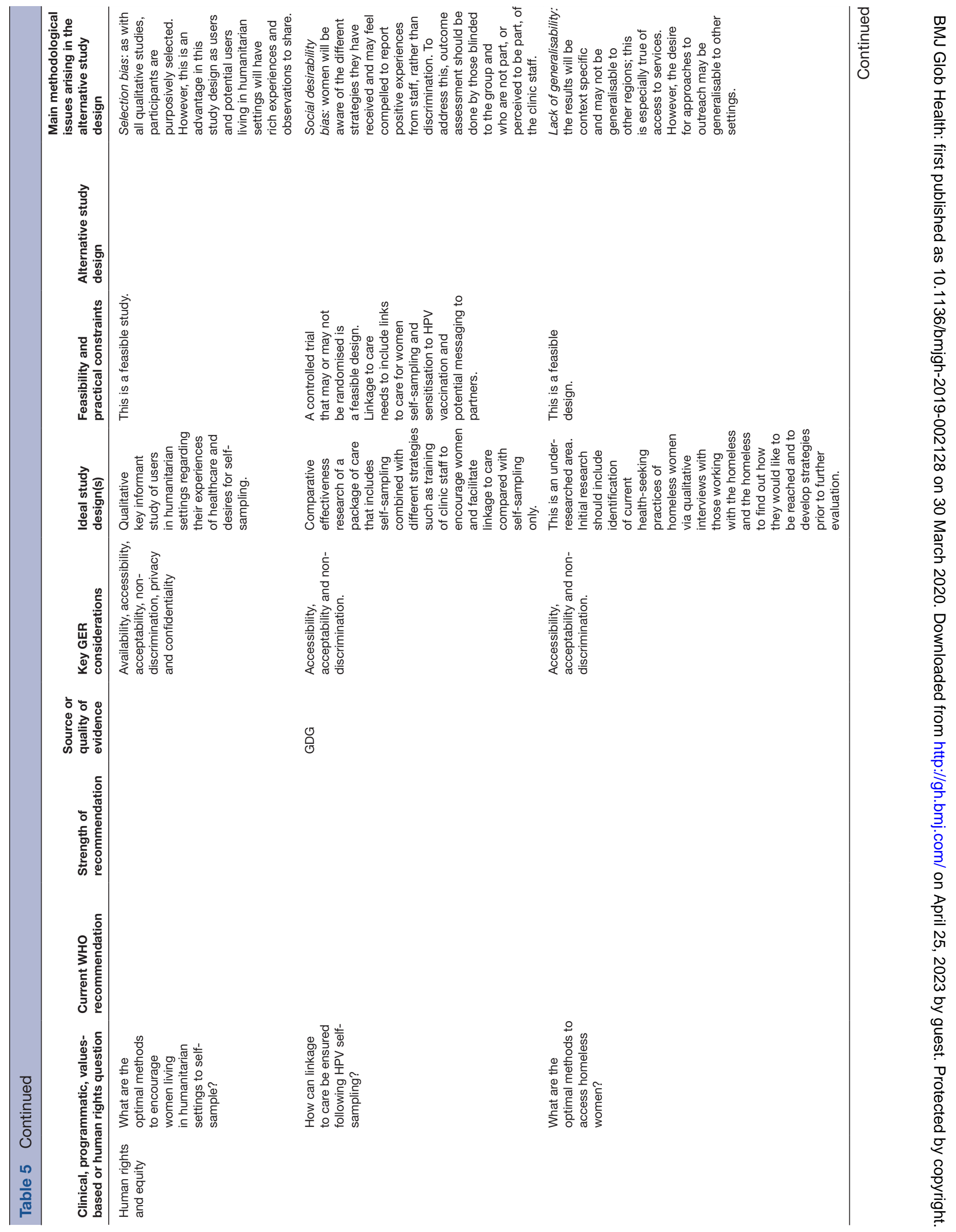




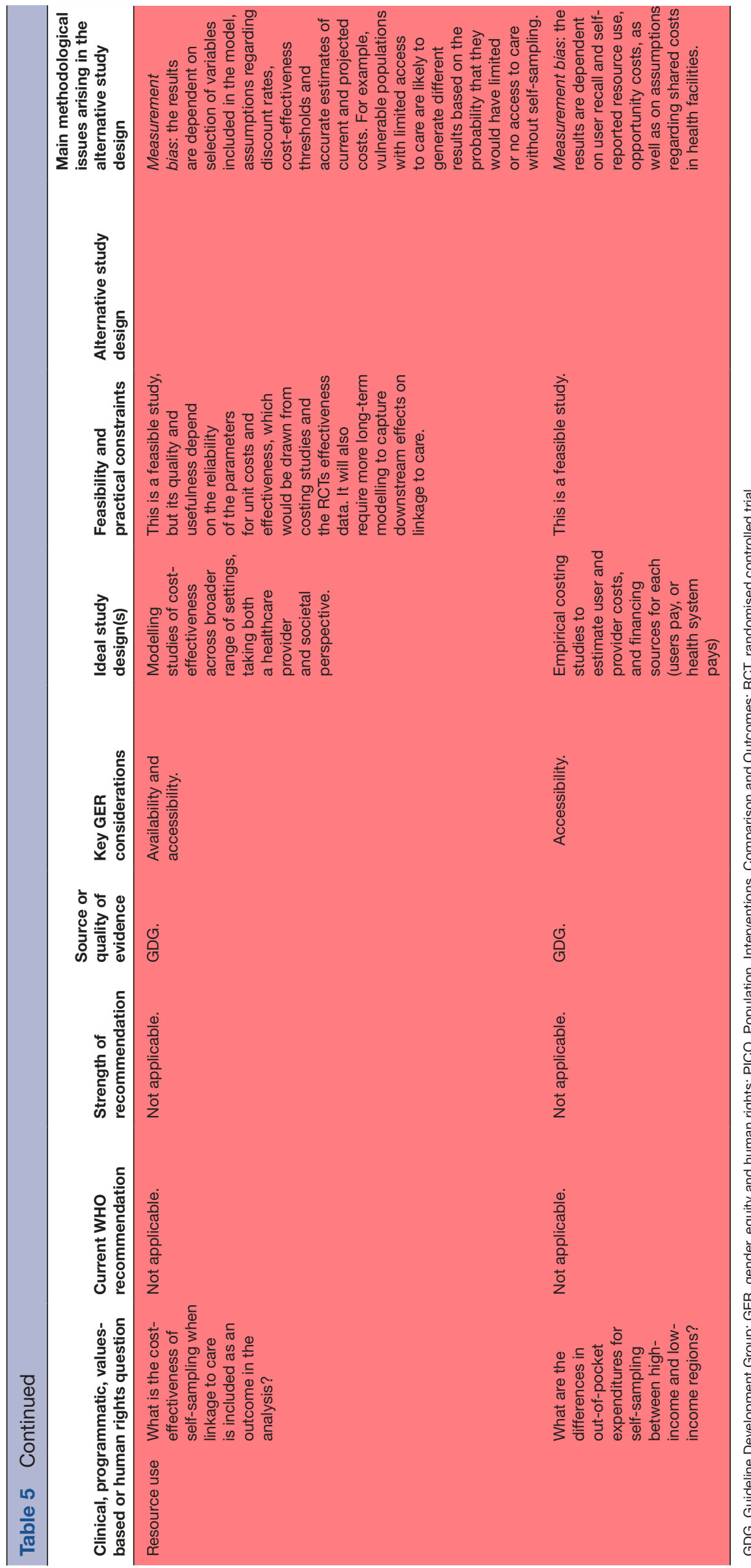

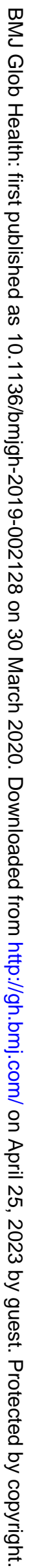




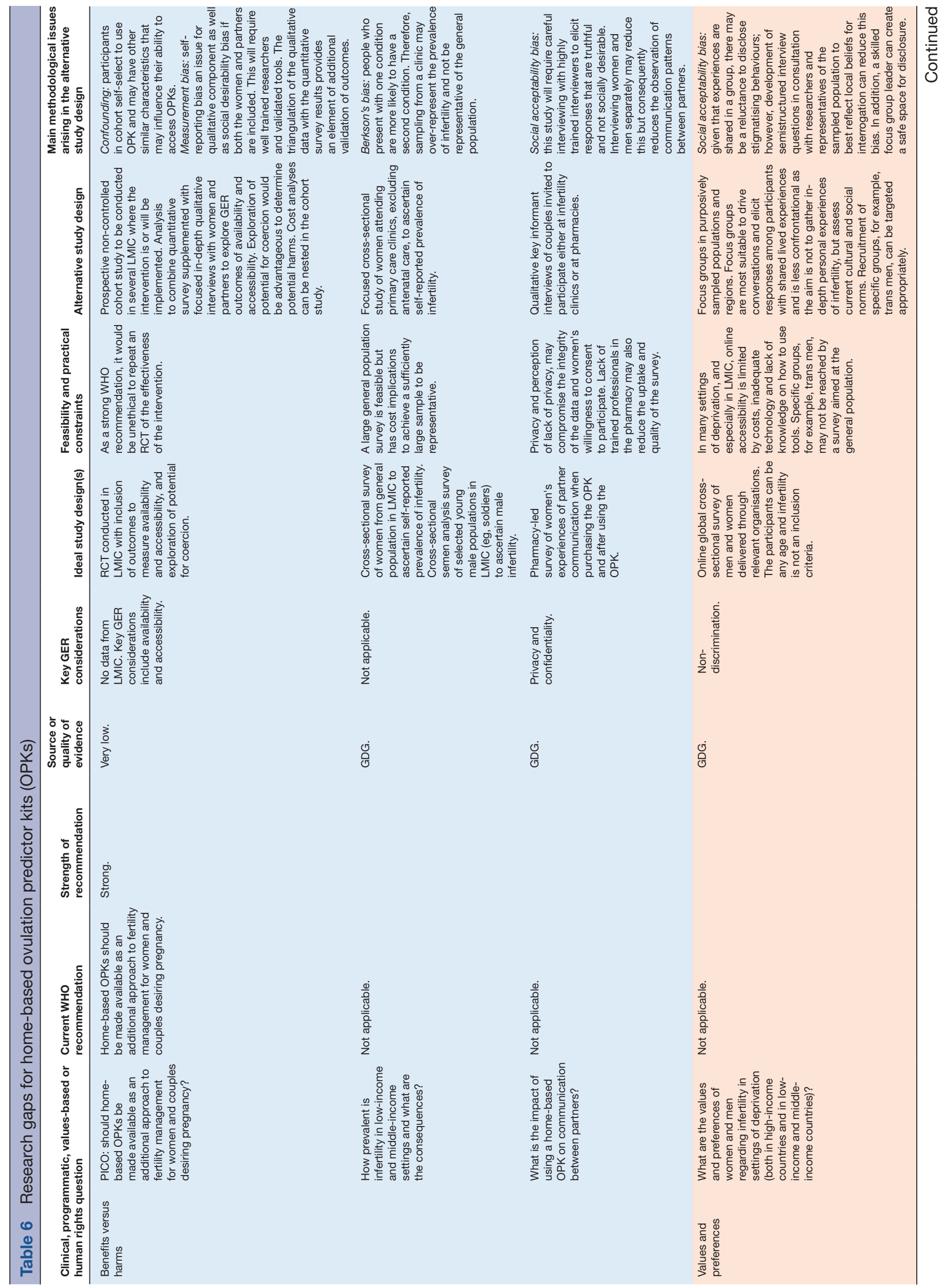




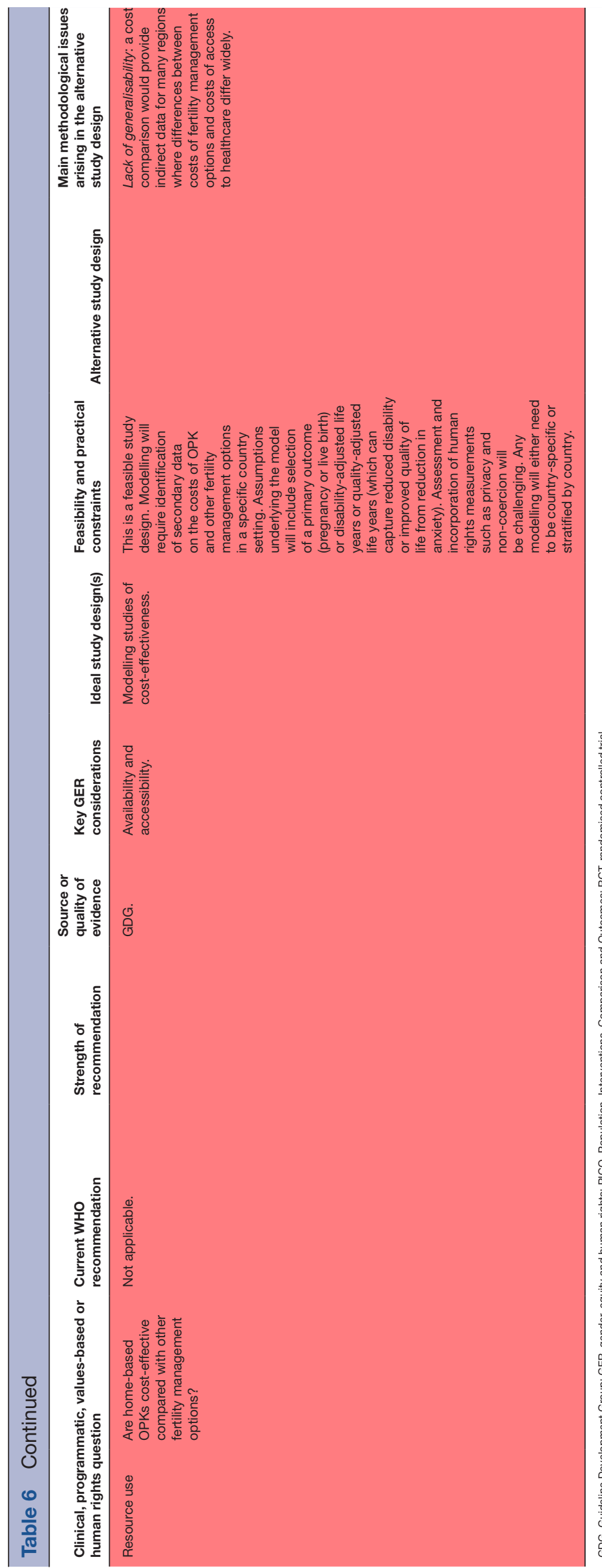

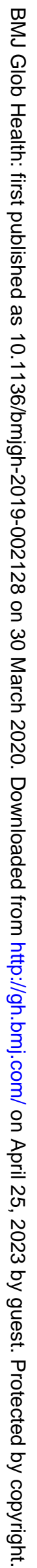


contraception uptake (measured by the proportion of users who were informed of potential side effects, what to do in the case of side effects and alternative contraceptive options). This highlights the human rights standard of acceptability as well as the principle of autonomy, expressed through free, full and informed decision making. ${ }^{27}$ Similarly, indicators commonly used in the fields of GER may be used to measure certain aspects of sexual and reproductive health; for example, measures of the existence, content and degree of implementation of relevant laws and policies governing access to sexual and reproductive health information and services can help elucidate patterns in uptake of services, including for self-care initiatives. An indicator that incorporates both sets of concern will allow for identification of interventions that are sensitive to issues relating to GER and most effective in terms of improving health. ${ }^{26}$

In our approach, we identified the GER standards and principles most relevant to each question but did not operationalise measurement. This is an important next step. Development of, and agreement on, standardised indicators and the optimal instruments to measure these within the SRHR self-care intervention field will greatly enhance the usability and uptake of GER-informed evidence into future guidelines through streamlining meta-analysis and synthesis more broadly. The experience and guidance of the Core Outcome Measures in Effectiveness Trials (COMET) initiative are instructive in this regard. COMET advocates for the development and application of agreed, standardised sets of outcomes, known as 'core outcome sets', which represent the minimum that should be measured and reported in all clinical trials of a specific condition and are also suitable for use in clinical auditing or research other than randomised trials. ${ }^{28}$ Inclusion of GER in an SRHR self-care core outcome set will ensure GER are integral to all future evaluations. We welcome initiatives to bring researchers from the human rights, gender, health economics and epidemiology fields together to advance this.

The WHO aims to be representative when determining GDG composition, and for the guideline on self-care interventions, we believe reasonable representation was achieved. However, in general, the balance is in favour of healthcare providers rather than community members and users of interventions. We were also able to ensure participation of users and healthcare providers of SRHR self-care interventions by incorporating the findings of the global survey and focus group discussions with vulnerable populations into the formulation of research gaps. Active and informed participation of users is also an important consideration during implementation of recommendations and in planning future research studies. Many of the proposed future studies are focused on vulnerable populations, and participation in the study or assessment of an outcome may place participants at risk. This illustrates that outcome measurement and the process of research itself requires careful consideration of GER to minimise unintended harms. Community-based participatory research is a useful strategy to conducting research that is relevant, appropriate and acceptable.

Prior to conducting studies on self-care, researchers need to consider the burdens faced by study participants, particularly for implementation research and qualitative methodologies. There is an opportunity cost to participants who may have to take time away from work or family care in order to contribute to research activities. We encourage meaningful involvement of individuals or groups representing target populations in the design and cocreation of research methodologies to optimise benefits to individuals and the wider group while minimising burdens to the participants. This approach is supported by ethical considerations ${ }^{29}$ and several frameworks that promote person-centred interventions. ${ }^{30} 31$

Each of the proposed study designs can be further expanded into a template for a study protocol and made publicly available. The WHO successfully achieved rapid deployment of ethically approved clinical trial protocols for the Ebola vaccine under emergency conditions. ${ }^{32} 33$ Under more controlled conditions, WHO may consider systematically developing field-specific study protocol templates that meet ethics standards. Researchers can then modify these templates to their context addressing any specific local ethics requirements before rapidly conducting studies during implementation of new WHO recommendations to inform programme scale-up or for testing new strategies well in advance of planned future GDG meetings.

Similar to our previous work where we applied the original framework to SRHR guidelines for women living with HIV, we found that many of the identified research questions require evaluation of complex, multifaceted and often multisectoral interventions that may be best suited to evaluation within an implementation research paradigm. ${ }^{12}$ Implementation science provides a platform to learn whether an intervention works in real-world settings and demonstrates how to ensure an intervention can effectively be brought to scale. Importantly, outcomes such as acceptability, feasibility and costs are encouraged in addition to conventional measures of effectiveness. ${ }^{34}$ RCTs are the optimal design for providing evidence of efficacy and will remain the gold standard for informing WHO recommendations. However, comparative effectiveness research (CER) where available interventions are compared with each other (instead of with usual care or placebo) can be viewed as a bridge between RCTs and implementation research. ${ }^{35}{ }^{36}$ Five of our research questions are best evaluated using CER (eg, comparison on OPKs with other fertility management options) with 10 studies requiring a multistudy approach best articulated in implementation science. The challenge for $\mathrm{WHO}$ will be how these types of study designs and approaches can best be incorporated into future WHO guidelines decision making. Some progress has been made with the inclusion of the Risk of Bias in Non-randomised studies of interventions (ROBINS-I) tool for assessing risk of bias in non-randomised studies in GRADE, ${ }^{36}$ guidance 
for rating certainty of evidence when reviewing public health interventions ${ }^{37}$ and the development of the WHOINTEGRATE framework to WHO guidelines development that includes specific methods to incorporate norms and values and a greater complexity perspective. ${ }^{38}$

Our approach is unique to the development of normative guidance. As such it is limited by the scope of a guideline, which may be intentionally narrow due to feasibility, resources and time constraints. The research gaps arising from such a process are specific to the scope of the guidelines and should not be viewed as a comprehensive research agenda for the relevant clinical or public health field nor as a research prioritisation exercise. However, the resultant research questions can provide a baseline list of questions that can then be further subjected to one of several research prioritisation methodologies. ${ }^{39-41}$

Lastly, while our overall decision-making process is structured and systematised, the selection of the most relevant GER standards and principles was done primarily through iterative discussion and ultimately consensus between study authors. Such decisions may not readily lend themselves to standardised processes, but we would advocate that in order to ensure the integrity and generalisability of the selected standards and principles, decisions should be made by a diverse and representative group as possible. We attempted to do so by reflecting a diversity of backgrounds, skills and experiences among the study authors, but we acknowledge that our selections are nonetheless subjective and may be best done by the broader GDG. Further exploration and development of ways to standardise such decisions such as initiated in the family planning field is now required. ${ }^{42}$

\section{CONCLUSION}

A framework based on GRADE that includes stakeholders' values and identification of core GER standards and principles provides a practical, systematic approach to identifying research questions from a WHO guideline. Uptake of this framework has the potential to harmonise methods and ensure more consistent consideration of research question formulation across the organisation. Clear guidance for future studies, including anticipation of, and methods to reduce risks of bias, can contribute to an anticipated 'living guidelines' approach within WHO. Foregrounding GER as a separate component of the framework is key to ensuring it is considered as integral to outcome evaluation, and further elaboration to operationalise appropriate indicators for SRHR self-care interventions is required.

\footnotetext{
Author affiliations

${ }^{1}$ Independent Clinical Epidemiologist, Cape Town, South Africa

${ }^{2}$ Department of Sexual and Reproductive Health and Research, including UNDPUNFPA-UNICEF-WHO-World Bank Special Programme of Research, Development and Research Training in Human Reproduction, World Health Organization, Geneva, Switzerland

${ }^{3}$ Factor-Inwentash Faculty of Social Work, University of Toronto, Toronto, Ontario, Canada
}

${ }^{4}$ Guideline Review Committee Secretariat (Science Division), World Health Organization, Geneva, Switzerland

${ }^{5}$ Institute on Inequalities in Global Health, Keck School of Medicine, University of Southern California, Los Angeles, California, USA

${ }^{6}$ Independent Consultant, Amsterdam, The Netherlands

${ }^{7}$ International Institute for Global Health, United Nations University, Kuala Lumpur, Malaysia

Acknowledgements The authors are grateful to all members of the Guidelines Development Group for their contributions during the meeting. We would like to thank Rachel Beanland, Independent Public Health Consultant, for her helpful comments on the selection of study designs and elaboration of biases.

Contributors NS conceived the concept and developed the framework and methodology informed by prior work in the area. MN led the WHO guideline development process and initiated the use of the framework during the guideline process. All authors contributed to refining the framework and provided expertiseinformed contributions to adapting the framework, formulating research questions and identifying study designs. All authors contributed to the final manuscript.

Funding This paper was funded by WHO/UNDP-UNFPA-UNICEF-WHO-World Bank Special Programme of Research, Development and Research Training in Human Reproduction (HRP). The authors alone are responsible for the views expressed in this article and they do not necessarily represent the views, decisions or policies of the institutions with which they are affiliated.

Competing interests None declared.

Patient and public involvement Patients and/or the public were involved in the design, or conduct, or reporting, or dissemination plans of this research. Refer to the Methods section for further details.

Patient consent for publication Not required.

Provenance and peer review Not commissioned; externally peer reviewed.

Data availability statement The article describes development and application of a framework. The tables generated regarding study design may constitute data and are included in the published manuscript.

Open access This is an open access article distributed in accordance with the Creative Commons Attribution 4.0 Unported (CC BY 4.0) license, which permits others to copy, redistribute, remix, transform and build upon this work for any purpose, provided the original work is properly cited, a link to the licence is given, and indication of whether changes were made. See: https://creativecommons.org/ licenses/by/4.0/.

\section{ORCID iD}

Nandi Siegfried http://orcid.org/0000-0002-4081-1698

\section{REFERENCES}

1 World Health Organization. WHO Handbook for Guideline development. 2nd edn, 2014. Available: https://www.who.int/ publications/guidelines/guidelines_review_committee/en/ [Accessed 19 Mar 2020]

2 Maher D, Ford N. A public health research agenda informed by guidelines in development. Bull World Health Organ 2017;95:795-A.

3 World Health Organization. WHO consolidated guideline on self-care interventions for health: sexual and reproductive health and rights. Geneva: World Health Organization, 2019Licence: CC BY-NC-SA 3.0 IGO

4 Hatch S IK. Self-help and health in Europe: new approaches in health care. Albany, NY: World Health Organization Publications Center USA, 1983.

5 World Health Organization. WHO meeting on ethical, legal, human rights and social accountability implications of self-care interventions for sexual and reproductive health: 12-14 March 2018, Brocher Foundation, Hermance, Switzerland: summary report. Geneva: World Health Organization, 2018. Licence: CC BY-NC-SA 3.0 IGO.

6 World Health Organization. Gender, equity and human rights, 2019. Available: https://www.who.int/gender-equity-rights/understanding/ human-rights-definition/en/ [Accessed 5 Jun 2019].

7 World Health Organization. A human-rights based approach to health. Available: https://www.who.int/hhr/news/hrba_to_health2.pdf [Accessed 22 Aug 2019].

8 Sridharan S, Maplazi J, Shirodkar A, et al. Incorporating gender, equity, and human rights into the action planning process: moving from rhetoric to action. Glob Health Action 2016;9:30870. 
9 Ferguson L, Fried S, Matsaseng T, et al. Human rights and legal dimensions of self care interventions for sexual and reproductive health. BMJ 2019;365:I1941.

10 World Health Organization. WHO consolidated guideline on self-care interventions for health: sexual and reproductive health and rights web supplement: global values and preferences survey report. Geneva: World Health Organization, 2019. https://apps.who.int/iris/ bitstream/handle/10665/329989/WHO-RHR-19.24-eng.pdf?ua=1

11 Siegfried N, Beanland RL, Ford N, et al. Formulating the future research agenda for postexposure prophylaxis for HIV: methodological challenges and potential approaches. Clin Infect Dis 2015;60(Suppl 3):S205-11.

12 Siegfried N, Narasimhan M, Kennedy CE, et al. Using GRADE as a framework to guide research on the sexual and reproductive health and rights (SRHR) of women living with HIV - methodological opportunities and challenges. AIDS Care 2017;29:1088-93.

13 Yeh PT, Kennedy CE, Van der Poel S, et al. Should home-based ovulation predictor kits be offered as an additional approach for fertility management for women and couples desiring pregnancy? A systematic review and meta-analysis. BMJ Glob Health 2019;4:e001403.

14 Yeh PT, Kennedy CE, de Vuyst H, et al. Self-sampling for human papillomavirus (HPV) testing: a systematic review and meta-analysis. BMJ Glob Health 2019;4:e001351.

15 Ogale Y, Yeh PT, Kennedy CE, et al. Self-collection of samples as an additional approach to deliver testing services for sexually transmitted infections: a systematic review and meta-analysis. BMJ Glob Health 2019;4:e001349.

16 Kennedy CE, Yeh PT, Gonsalves L, et al. Should oral contraceptive pills be available without a prescription? A systematic review of over-the-counter and pharmacy access availability. BMJ Glob Health 2019;4:e001402

17 Kennedy CE, Yeh PT, Gaffield ML, et al. Self-administration of injectable contraception: a systematic review and meta-analysis. BMJ Glob Health 2019;4:e001350.

18 Guyatt GH, Oxman AD, Vist GE, et al. GRADE: an emerging consensus on rating quality of evidence and strength of recommendations. BMJ 2008;336:924-6.

19 Andrews JC, Schünemann HJ, Oxman AD, et al. Grade guidelines: 15. going from evidence to recommendation-determinants of a recommendation's direction and strength. J Clin Epidemiol 2013;66:726-35

20 Robinson KA, Saldanha IJ, McKoy NA. Frameworks for determining research gaps during systematic reviews. In: Methods future research needs report No. 2. Rockville MD: Agency for Healthcare Research and Quality, 2011. www.effectivehealthcare.ahrq.gov/ reports/final.cfm

21 Dechartres A, Ravaud P. Better prioritization to increase research value and decrease waste. BMC Med 2015;13:244.

22 Akl EA, Meerpohl JJ, Elliott J, et al. Living systematic reviews: 4 living guideline recommendations. J Clin Epidemiol 2017;91:47-53.

23 World Health Organization. Ensuring human rights in the provision of contraceptive information and services: guidance and recommendations, 2019. Available: https://apps.who.int/ iris/bitstream/handle/10665/102539/9789241506748 eng.pdf; jsessionid=36DDE4C1852D56BB855F5082C1436DA7? sequence $=1$ [Accessed 30 Sep 2019].

24 World Health Organization. Reproductive, maternal, newborn and child health and human rights: a toolbox for examining laws, regulations and policies, 2016. Available: https://apps.who.int/ iris/bitstream/handle/10665/126383/9789241507424 eng.pdf; jsessionid=7A1BFE94AB8933086237F6D385966381 ? sequence $=1$ [Accessed 30 Sep 2019].
25 UN Committee on Economic, Social and Cultural Rights (CESCR). General Comment No. 14: the right to the highest attainable standard of health (art. 12 of the covenant), 11 August 2000, E/C.12/2000/4. Available: https://www.refworld.org/docid/ 4538838d0.html [Accessed 10 Sep 2019].

26 Gruskin S, Ferguson L. Using indicators to determine the contribution of human rights to public health efforts. Bull World Health Organ 2009;87:714-9.

27 World Health Organization. Ensuring human rights within contraceptive programmes: a human rights analysis of existing quantitative indicators, 2014. Available: https://apps.who.int/iris/ bitstream/handle/10665/126799/9789241507493_eng.pdf?ua=1\& $\mathrm{ua}=1$ ? sequence $=1$ [Accessed 8 Oct 2019].

28 Williamson PR, Altman DG, Bagley $\mathrm{H}$, et al. The COMET Handbook: version 1.0. Trials 2017;18:280.

29 Aluwihare-Samaranayake D. Ethics in qualitative research: a view of the participants' and researchers' world from a critical standpoint. Int J Qual Methods 2012;11:64-81.

30 Narasimhan M, Allotey P, Hardon A. Self care interventions to advance health and wellbeing: a conceptual framework to inform normative guidance. BMJ 2019;365:1688.

31 World Health Organization. Who framework on integrated personcentred services. Sixty-ninth World health assembly A69/39, 2016. Available: https://www.who.int/servicedeliverysafety/areas/peoplecentred-care/Overview_IPCHS_final.pdf?ua=1 [Accessed 20 Sep 2019].

32 Calain P. The Ebola clinical trials: a precedent for research ethics in disasters. J Med Ethics 2018;44:3-8.

33 Heymann DL, Rodier GR, Ryan MJ. Ebola vaccines: keep the clinical trial protocols on the shelf and ready to roll out. Lancet 2015;385:1913-5.

34 Peters DH, Adam T, Alonge O, et al. Implementation research: what it is and how to do it. BMJ 2013;347:f6753.

35 Glasgow RE, Rabin BA. Implementation science and comparative effectiveness research: a partnership capable of improving population health. J Comp Eff Res 2014;3:237-40.

36 Schünemann HJ, Cuello C, Akl EA, et al. GRADE guidelines: 18. How ROBINS-I and other tools to assess risk of bias in nonrandomized studies should be used to rate the certainty of a body of evidence. $J$ Clin Epidemiol 2019;111:105-14.

37 Montgomery P, Movsisyan A, Grant SP, et al. Considerations of complexity in rating certainty of evidence in systematic reviews: a primer on using the grade approach in global health. BMJ Glob Health 2019;4:e000848.

38 Rehfuess EA, Stratil JM, Scheel IB, et al. The WHO-INTEGRATE evidence to decision framework version 1.0: integrating who norms and values and a complexity perspective. BMJ Glob Health 2019;4:e000844.

39 Nasser M, Welch V. Prioritization of systematic reviews leads prioritization of research gaps and needs. J Clin Epidemiol 2013;66:522-3

40 Nasser $M$, Ueffing $E$, Welch $V$, et al. An equity lens can ensure an equity-oriented approach to agenda setting and priority setting of Cochrane reviews. J Clin Epidemiol 2013;66:511-21.

41 Bhaumik S, Rana S, Karimkhani C, et al. Ethics and equity in research priority-setting: stakeholder engagement and the needs of disadvantaged groups. Indian J Med Ethics 2015;12:110-3.

42 Gruskin S, Ferguson L, Kumar S, et al. A novel methodology for strengthening human rights based monitoring in public health: family planning indicators as an illustrative example. PLoS One 2017;12:e0186330. 